\title{
Dual role of microcracks: toughening and degradation
}

\author{
G.M. Nagaraja Rao and C.R.L. Murthy
}

\begin{abstract}
One of the methods of improving the mechanical properties of ceramics is to introduce a defective structure that acts as a restraint for the propagation of cracks. In the present study a detailed investigation was carried out by introducing a defective structure in rock to determine if there is any improvement in properties similar to ceramics. Granite was chosen for the investigation, and the microcracks were introduced by a heating and cooling cycle. Uniaxial compression tests have shown that granite thermally treated to $200^{\circ} \mathrm{C}$ shows the highest strength, and the strength of granite treated to $400^{\circ} \mathrm{C}$ is comparable to that of unheated granite. Both ultrasonic images and acoustic-emission monitoring show that for thermally treated samples the stress-induced microcrack and macrocrack nucleation and their growth are retarded. The variations in mechanical properties are explained based on the concept of toughening and degradation. Uniaxial compression tests on unheated and thermally treated granite samples have clearly established the dual role of microcracks, which operate in the toughening and degradation mechanisms.
\end{abstract}

Key words: thermal treatment, microcrack, inelastic strain, ultrasonic C-scan imaging, acoustic emission, toughening.

Résumé : Une des méthodes pour améliorer les propriétés mécaniques des céramiques est d'introduire une structure avec défaut qui agit comme une entrave à la propagation des fissures. Dans la présente étude, une étude détaillée a été réalisée en introduisant un défaut de structure dans la roche pour savoir s'il y a quelque amélioration dans les propriété telle qu'observée dans les céramiques. À cet fin, le granite a été choisi pour l'étude, et les microfissures ont été provoquées par un cycle de chauffage et de refroidissement. Des essais de compression uniaxiale ont montré que le granite ayant eu un traitement thermique à $200^{\circ} \mathrm{C}$ avaient une résistance plus élevée, alors que la résistance du granite traité à $400^{\circ} \mathrm{C}$ est comparable à la résistance d'un granite non chauffé. Tant les images ultrasoniques que les mesures d'émission acoustique montrent que, pour les échantillons ayant subi un traitement thermique, la contrainte induisait de la nucléation de micro et macrofissures et leur propagation était retardée. La variation de leurs propriétés mécaniques est expliquée sur la base du concept de durcissement et de dégradation. Les essais de compression triaxiale sur les échantillons de granite non chauffés et ceux avec traitement thermique ont établi clairement le double rôle des microfissures qui agissent dans les mécanismes de durcissement et de dégradation.

Mots clés : traitement thermique, microfissure, déformation inélastique, imagerie ultrasonique à balayage, émission acoustique, durcissement.

[Traduit par la Rédaction]

\section{Introduction}

Rocks are natural engineering materials containing metal and nonmetal oxides bonded by ionic and covalent bonds. They are classified as brittle materials under normal laboratory temperature and pressure conditions. They show plastic behaviour under high temperature and pressure conditions. Among synthetic engineering materials including metals, ceramics, plastics, and composites, the mechanical behaviour of ceramics is similar to that of rocks. Ceramics contain ox-

Received February 2, 2000. Accepted October 17, 2000.

Published on the NRC Research Press Web site on April 17, 2001.

G.M. Nagaraja Rao. ${ }^{1}$ Rock Fracture Mechanics and Materials Testing Laboratory, National Institute of Rock Mechanics, Kolar Gold Fields, Karnataka 563 117, India. C.R.L. Murthy. Indian Institute of Science, Bangalore 560012 , India.

${ }^{1}$ Corresponding author (e-mail: nirm@vsnl.com). ides, borides, carbides, etc. bonded by ionic and covalent bonds.

Ceramics are also brittle like rock materials. As both ceramics and rocks contain oxides and their mechanical behaviours are similar, we can refer to rocks as natural ceramics. One of the methods of improving the mechanical properties of ceramics is by introducing a defective structure that acts as an effective restraint for crack propagation and thus enhances the material toughness (Lawn 1993). Keeping this analogy in the present study, an attempt was made to determine if the introduction of a defective structure in rocks will improve their mechanical properties similar to those of ceramics. Defective structure means the introduction of microcracks into the rock matrix. This is achieved by subjecting the rock to thermal treatment, that is, a heating and cooling cycle.

Rocks are polycrystalline, containing minerals with different thermal expansion coefficients. When rock is heated, stresses are developed because of the difference in the thermal expansion coefficients between the minerals, and within each mineral because the expansion varies along its crystallographic 
directions. If these stresses exceed the local strength, microcracks develop. During cooling, microcracks are produced due to contraction of the minerals. Microcracks produced during the heating and cooling cycle affect the physical and mechanical properties, and a large amount of information is available in the literature, with a few of the findings reported here.

Alm et al. (1985) investigated the effect of microcracks produced by thermal shocks on the mechanical properties of Stripa granite. Shock heating of samples of Stripa granite was carried out at temperatures of 100, 150, 200, 300, 450, and $600^{\circ} \mathrm{C}$ for $3 \mathrm{~h}$; after cooling, their mechanical properties were determined. Crack density increased with an increase in the temperature of thermal treatment, as determined using the ultrasonic velocity method. The most interesting observation is that the uniaxial compressive strength was highest for the sample preheated to $450^{\circ} \mathrm{C}$, although most of its grains are microcracked.

Etienne and Poupert (1989) carried out uniaxial compression tests on thermally treated granites. Remiremont and Sennones granite were thermally cracked to temperatures of 200,400 , and $600^{\circ} \mathrm{C}$ for $5 \mathrm{~h}$. The crack density was determined using a scanning electron microscope. The increase in crack density with an increase in temperature was greatest for the Sennones granite. The modulus of elasticity of both granites decreased with an increase in temperature, as expected. The Remiremont granite at $200^{\circ} \mathrm{C}$ showed slightly higher strength than the untreated sample, but the Sennones granite showed an increase in strength compared with the untreated sample at $400^{\circ} \mathrm{C}$. Crack density measurements by scanning electron microscope showed an increase in crack density with an increase in thermal treatment temperature, with the Sennones granite showing a higher crack density than the Remiremont granite. The increase in strength at $400^{\circ} \mathrm{C}$ is similar to observations reported by Alm et al. (1985).

Bauer and Johnson (1979) observed that the strength granite thermally treated to $400^{\circ} \mathrm{C}$ was slightly lower than that of the untreated granite.

Duclos and Paquet (1991) studied the effect of thermally induced damage in the case of annealed basalt and observed a maximum strength at $200^{\circ} \mathrm{C}$.

From the available literature it is apparent that thermal treatment does affect the mechanical properties depending upon the rock type and the treatment temperature. Microcracks introduced during thermal treatment can increase or decrease the strength of the rock. It is easy to explain the decrease in strength but difficult to provide an explanation for the increase in strength. Keeping this in view, detailed experiments were carried out to study the effect of thermally induced microcracks on the strength of rock and the growth of stress-induced microcracks under uniaxial compressive stress conditions, and the results were compared with those of the unheated stage. The following methodologies were used to understand the role of thermally induced microcracks: $(i)$ measurement of deformation and strength, (ii) ultrasonic C-scan imaging, and (iii) acousticemission (AE) monitoring.

Granite was chosen for the investigation because this rock type is fairly homogeneous and free from natural defects, like cracks and joints, and porosity is less than $1 \%$. Petrographically, the rock consists mainly of plagioclase (37\%),
Table 1. $P$-wave velocity of unheated and thermally treated granite.

\begin{tabular}{ll}
\hline $\begin{array}{l}\text { Thermal treatment } \\
\text { temperature }\left({ }^{\circ} \mathrm{C}\right)\end{array}$ & $\begin{array}{l}P \text {-wave velocity } \\
(\mathrm{km} / \mathrm{s})\end{array}$ \\
\hline 28 & 4.15 \\
200 & 3.84 \\
400 & 2.88 \\
\hline
\end{tabular}

quartz (31\%), and microcline (18\%). The mafic constituents biotite, hornblende, and chlorite constitute less than $15 \%$ of the composition of granite. To study the effect of heat exposure three temperatures were selected, namely $200^{\circ} \mathrm{C}$, $400^{\circ} \mathrm{C}$, and room temperature of about $28^{\circ} \mathrm{C}$. It is reported in the literature that the microcracking occurs in granite at about $80-120^{\circ} \mathrm{C}$, and most of the mineral grains are microcracked at about $400^{\circ} \mathrm{C}$ (Bauer and Johnson 1979). Hence $28^{\circ} \mathrm{C}, 200^{\circ} \mathrm{C}$, and $400^{\circ} \mathrm{C}$ are sufficient to produce a large variation in the density of microcracks. The heat exposure was maintained for $24 \mathrm{~h}$ so that the temperature was homogeneous throughout the sample and the time was sufficient to introduce the effects of thermal exposure. Table 1 gives the $P$-wave velocity of unheated and thermally treated samples. With the increase of thermal treatment temperature the $P$-wave velocity decreases, indicating that thermal treatment produces microcracks.

\section{Deformation and strength}

NX size (is $54.7 \mathrm{~mm}$ diameter) samples were drilled from a single granite block, cut to the desired length, and ground and polished using a surface grinder. The dimensional tolerances were maintained according to the International Society for Rock Mechanics (ISRM) suggested method. The length to diameter ratio was kept at approximately 2.5. Prepared rock core samples were heated in a furnace to $200^{\circ} \mathrm{C}$ and $400^{\circ} \mathrm{C}$ for $24 \mathrm{~h}$. The rate of heating was about $2^{\circ} \mathrm{C} / \mathrm{min}$. At the end of $24 \mathrm{~h}$ the samples were removed and then cooled in a desiccator. Uniaxial compression tests were carried out using the servocontrolled hydraulic MTS compression testing machine with load control at a rate of $47 \mathrm{kN} / \mathrm{min}$. Axial and lateral strains were recorded using MTS extensometers. For each temperature a minimum of five samples were tested.

Figure 1 shows the relationship between axial strain and lateral strain with respect to stress for unheated and thermally treated samples. Since the stress-strain curves appear to be identical for all the tested samples, only one set of curves is shown in Fig. 1.

With an increase in stress under uniaxial compression, microcracks initiate, grow, and coalesce to form macroscopic cracks. From the stress-strain curves it is possible to draw qualitative observations on the growth of stressinduced microcracks. Figure 1 shows that with the increase of thermal treatment temperature, axial strain increases, which can be related to the increase in crack density due to thermal exposure. Lateral strain due to stress-induced microcracks decreases with an increase in thermal treatment temperature. Qualitatively lateral strain is a measure of microcrack development, as the cracks formed at an angle to the loading axis are registered in the lateral strain. Less 
Fig. 1. Uniaxial stress versus strain of unheated and thermally treated samples.

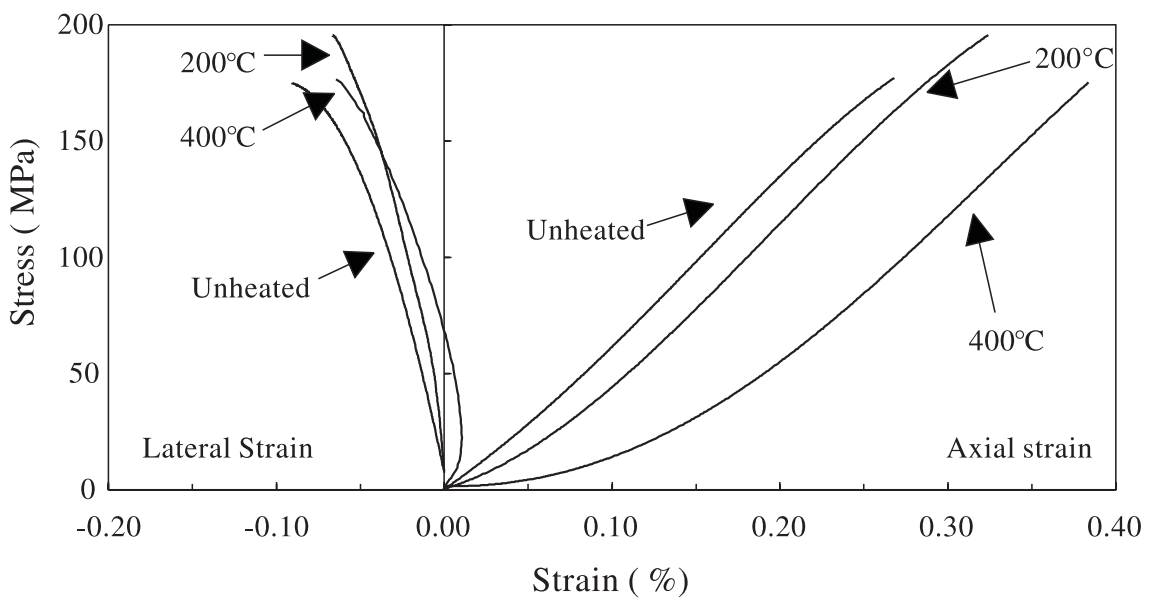

Fig. 2. Effect of thermal treatment on uniaxial compressive strength.

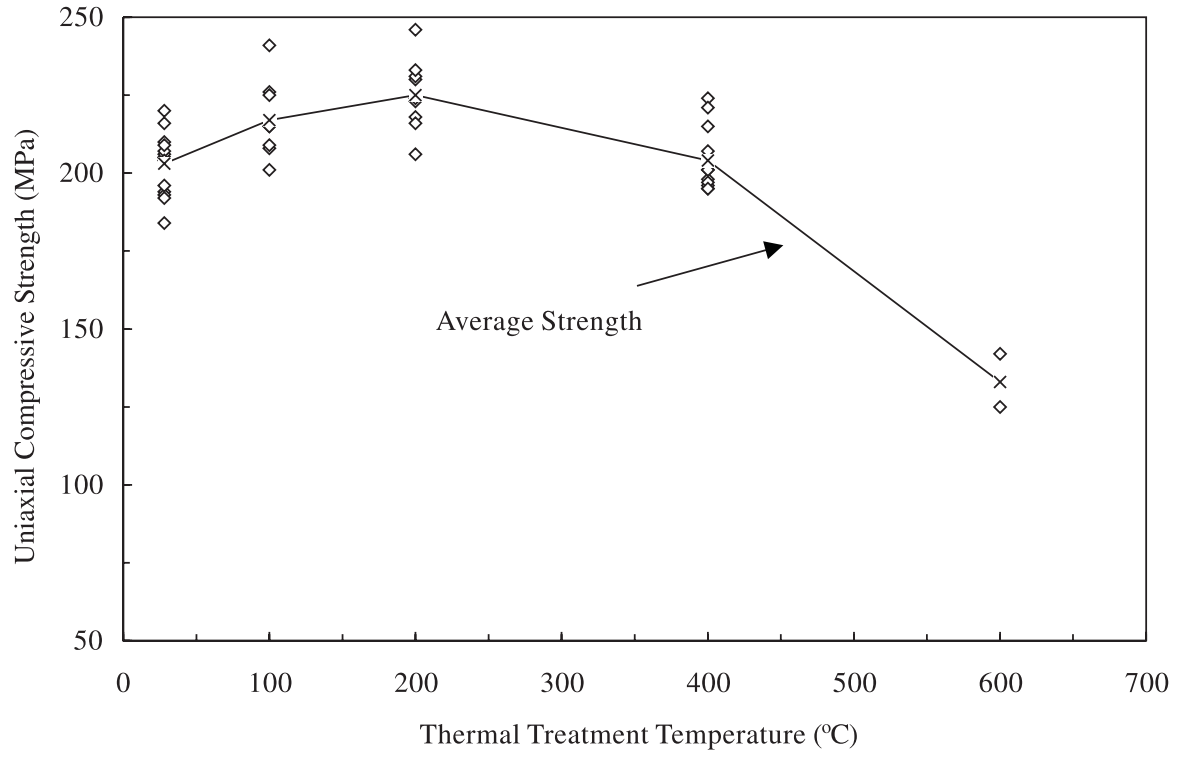

lateral strain for thermally treated samples implies that there is a mechanism resisting the initiation of stress-induced microcracks.

Young's modulus and Poisson's ratio were calculated from the linear portion of the stress-strain curve (60$80 \mathrm{MPa}$ ) and are presented in Table 2 for one set of samples. Table 2 shows that Young's modulus decreases with an increase in the thermal treatment temperature because of the increase in microcrack density. However, Poisson's ratio calculated for the sample thermally treated to $400^{\circ} \mathrm{C}$ is not accurate, as the lateral strain curve is always nonlinear.

Figure 2 shows the variation of uniaxial compressive strength for unheated and thermally treated samples. Here the strengths of samples thermally treated to $100^{\circ} \mathrm{C}$ and $600^{\circ} \mathrm{C}$ were also included to observe the trends. In Fig. 2 individual strength values are represented by symbols and the solid line shows the average strength value. Table 3 gives the values of average uniaxial compressive strength for unheated and thermally treated samples. Figure 2 shows that granite thermally treated to $200^{\circ} \mathrm{C}$ showed the highest strength and granite thermally treated to $600^{\circ} \mathrm{C}$ showed the lowest
Table 2. Elastic constant for unheated and thermally treated samples.

\begin{tabular}{lll}
\hline $\begin{array}{l}\text { Thermal treatment } \\
\text { temperature }\left({ }^{\circ} \mathrm{C}\right)\end{array}$ & $\begin{array}{l}\text { Young's modulus } \\
(\mathrm{GPa})\end{array}$ & $\begin{array}{l}\text { Poisson's } \\
\text { ratio }\end{array}$ \\
\hline 28 & 72 & 0.279 \\
200 & 69 & 0.202 \\
400 & 60 & 0.219 \\
\hline
\end{tabular}

strength. The strength of granite thermally treated to $400^{\circ} \mathrm{C}$ is comparable to that of the unheated granite. In some cases the strength of a sample thermally treated to $400^{\circ} \mathrm{C}$ is greater than that of the unheated sample.

\section{Inelastic strain}

As mentioned earlier in the paper, from the lateral strain curves it is possible to infer qualitatively the effect of thermal treatment on the growth of stress-induced microcracks. Quantitative information on the growth of microcracks can be obtained from the inelastic strain, which is a measure of microcrack development. The inelastic strain is computed 
Table 3. Average uniaxial compressive strength for thermally treated granite samples.

\begin{tabular}{ll}
\hline $\begin{array}{l}\text { Thermal treatment } \\
\text { temperature }\left({ }^{\circ} \mathrm{C}\right)\end{array}$ & $\begin{array}{l}\text { Compressive } \\
\text { strength }(\mathrm{MPa})\end{array}$ \\
\hline 28 & 203 \\
100 & 217 \\
200 & 225 \\
400 & 204 \\
600 & 133 \\
\hline
\end{tabular}

Fig. 3. Stress versus volumetric strain.

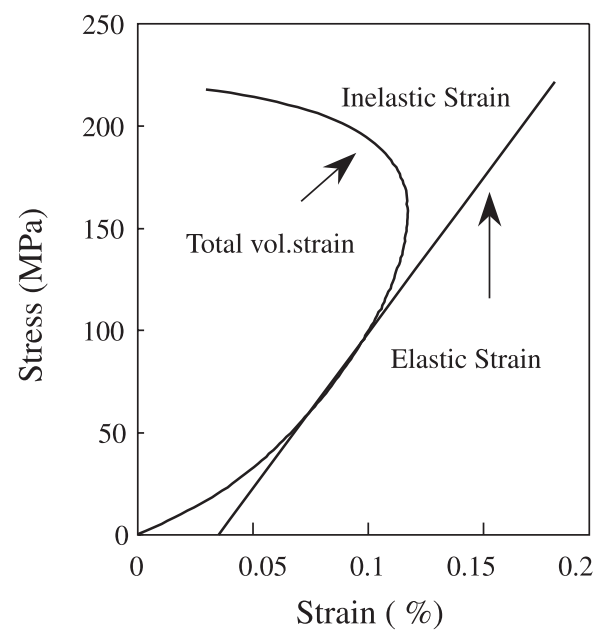

from the volumetric strain. The calculated volumetric strain consists of two parts, namely the elastic and inelastic components: calculated volumetric strain = elastic strain + inelastic strain.

The inelastic strain, which occurs due to microcrack development, is simply a difference between the calculated volumetric strain and the elastic volumetric strain (Kranz and Scholz 1977). The elastic volumetric strain is obtained by extrapolating the linear part of the stress - volumetric strain curve up to the fracture stress as shown in Fig. 3.

The inelastic strain was calculated for thermally treated samples and plotted as a function of stress in Fig. 4. The in- elastic strain (due to microcrack development) initially increases slowly and then exponentially with the increase in stress. The sources of inelastic strain are the nucleation and growth of microcracks and the formation and extension of macroscopic cracks. In the initial part of the curve, the inelastic strain is mainly due to stress-induced microcracks, and in the exponential part of the curve the contributions are from microcrack initiation and growth and the formation and extension of macroscopic cracks. For a given stress value the sample thermally treated to $200^{\circ} \mathrm{C}$ shows the lowest inelastic strain and that treated to $400^{\circ} \mathrm{C}$ shows the highest inelastic strain. The strain values of the unheated sample fall in between. The exponential region where crack coalescence and the initiation of macroscopic cracks occur is at a higher stress level in the case of the sample thermally treated to $200^{\circ} \mathrm{C}$. Inelastic strain, which is a measure of microcrack development, shows an anomalous trend for the sample thermally treated to $200^{\circ} \mathrm{C}$. The highest inelastic strain observed for the sample thermally treated to $400^{\circ} \mathrm{C}$ is due to the increase in crack density with the increase in temperature. Although the inelastic strain is high in the case of the sample treated to $400^{\circ} \mathrm{C}$, the uniaxial compressive strength is comparable to the strength of unheated granite.

From the results of uniaxial compression tests, it is evident that thermally induced microcracks affect the growth of stress-induced microcracks, the deformation, and the strength. More insight into the role of microcrack development is obtained from ultrasonic $\mathrm{C}$-scan imaging and $\mathrm{AE}$ monitoring and is explained in the following sections.

\section{Ultrasonic C-scan imaging of microcrack damage}

Ultrasonic C-scan imaging method is used widely to image the cracks and pores in ceramic materials, delaminations in composites, and defects in metallic materials (TomxGrubber et al. 1982; Knollman et al. 1975, 1978; Knollman and Hartog 1983; Knollman and Yee 1988). In rock mechanics a survey of the literature shows that not much work has been reported on imaging of cracks by the ultrasonic method. However, references are available on ultrasonic imaging of microcrack development in granitic rocks based on ultrasonic velocity measurements (Janson et

Fig. 4. Effect of thermal treatment on inelastic strain.

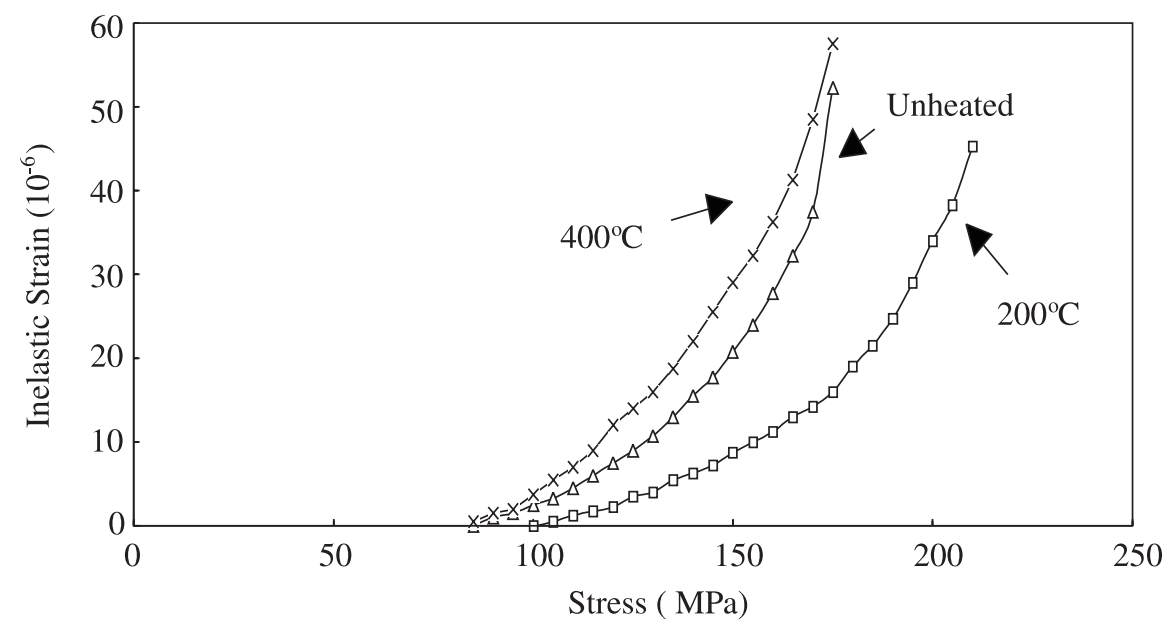


Fig. 5. Volumetric strain versus stress.

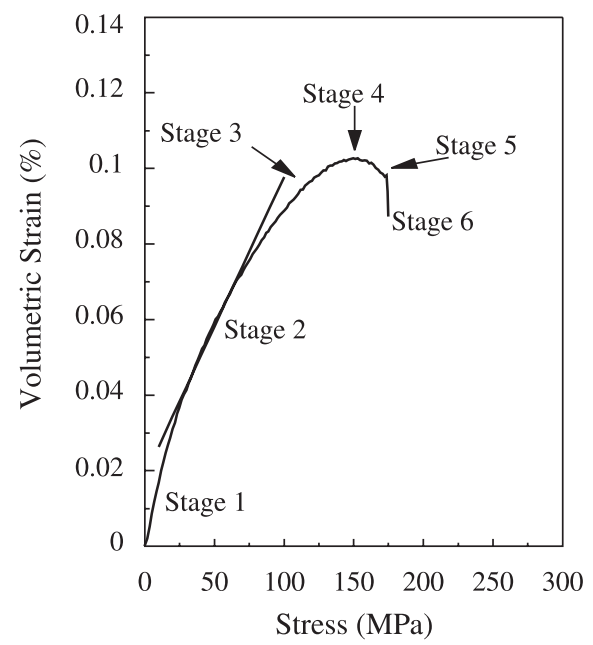

Fig. 6. Sectioning of the sample for imaging.
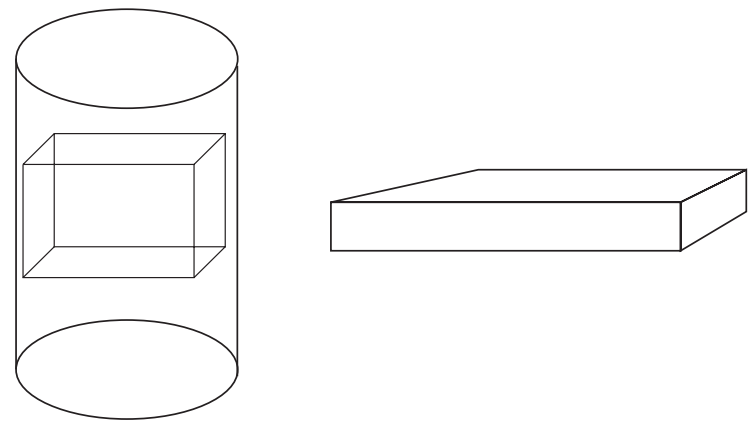

al. 1992, 1993; Falls et al. 1992; Young 1993). The advantages of the C-scan imaging method are (Nagaraja Rao et al. 1995) as follows: $(i)$ the size, shape, and orientation of the defective region can be mapped in a plan view; (ii) except for cutting, grinding, and polishing, laborious sample preparation is not required; (iii) the interior of a sample can be examined in a nondestructive manner; (iv) a large section of the sample can be examined, and it is possible to study how the crack distribution varies from location to location; and (v) the method is less time consuming.

\section{Characterization of microcrack development stages}

With the increase of stress, microcracks nucleate, propagate, and coalesce to form a macroscopic crack. These stages can be qualitatively inferred from the stress versus volumetric strain curve. Broadly, microcrack to macrocrack development can be divided into six stages (S1-S6) based on the volumetric strain curve as shown in Fig. 5: (S1) crack closure region; (S2) elastic deformation region; (S3) beginning of dilatancy, that is, initiation of new stress-induced microcracks; (S4) coalescence of microcracks at localized locations; (S5) microcrack coalescence and macroscopic crack nucleation and extension; and (S6) peak strength. The unstressed or unheated sample is designated as S0.

The first two stages are not important from the point of view of microcrack development, as new cracks are not produced in these regions, and stage 6 represents the peak strength. Stress-induced microcracks are produced in stages $3-5$, and these are the stages where major microcrack devel-
Fig. 7. Ultrasonic C-scan image of unheated granite.

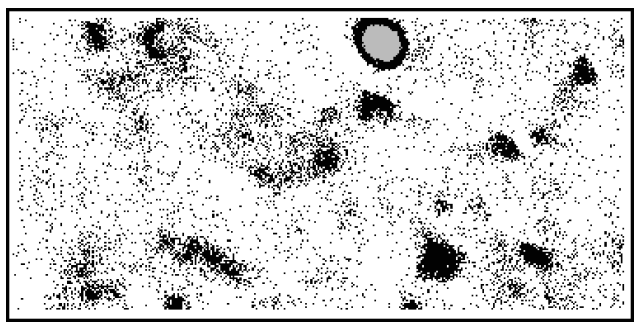

opment takes place and are the only stages considered for ultrasonic imaging. Since it was not practical to take the images at continuous intervals in a given stress range, ultrasonic images were taken towards the end of stages 3-5 of the stress versus volumetric strain curve, as major changes in microcrack development should be complete. It is not possible to load the same sample and image for various stages, so different samples prepared from a single block were used for each stage. Images considered are typical but would contain the trends in the microcrack development both qualitatively and quantitatively.

\section{Experimental details}

Ultrasonic C-scan imaging was carried out with an immersion medium, usually water, in which the transducer is attached to a precision scanner that can move in $x, y$, and $z$ directions under computer control. A point-focus transducer with a diameter of $13 \mathrm{~mm}, 5 \mathrm{MHz}$ center frequency, $7 \mathrm{MHz}$ bandwidth at $-6 \mathrm{~dB}$, and focal length of $75 \mathrm{~mm}$ in water was used for scanning. This point-focus type of transducer has a wide bandwidth and is suitable for rocks, which are a medium of high attenuation. The ultrasonic pulses generated by the electromechanical transducer travel through water, impinge on the surface of the specimen, and enter the material. The reflected pulses are amplified and digitized, and the images are constructed using suitable software and then stored on the hard disk of the computer. Details of the experimental setup are given by Nagaraja Rao (1996).

Cylindrical granite samples were thermally treated to $200^{\circ} \mathrm{C}$ and $400^{\circ} \mathrm{C}$ as explained earlier, loaded to stress levels corresponding to stages 3-5, and unloaded. The crack population and their distribution under uniaxial compression are higher parallel to the axis of loading than perpendicular to it. Hence samples were prepared to image the microcrack development parallel to the axis of loading, as it gives the highest crack density. The samples for compression testing were about $140 \mathrm{~mm}$ in length and $54 \mathrm{~mm}$ in diameter and were loaded to different stress levels (to stages 3-5) and unloaded. The unloaded sample is marked into three equal portions; from the mid-portion of the sample, a $10 \mathrm{~mm}$ thick sample was cut parallel to the axis of loading, ground, polished, and imaged across the thickness of the sample (Fig. 6). Due to high attenuation of ultrasonic waves in rock, the thickness of the sample for C-scan imaging was restricted to $10 \mathrm{~mm}$. The prepared samples were approximately $50 \mathrm{~mm} \times 30 \mathrm{~mm} \times 10 \mathrm{~mm}$. Images were also taken after thermal treatment to determine the increase in microcrack damage due to thermal exposure.

Ultrasonic waves are reflected from defects, and Fig. 7 shows a typical image obtained from an unstressed and unheated granite sample. The images are produced pixel by pixel (or point by point), and they do not have the normal 
Fig. 8. Ultrasonic C-scan images of unheated and thermally treated samples.

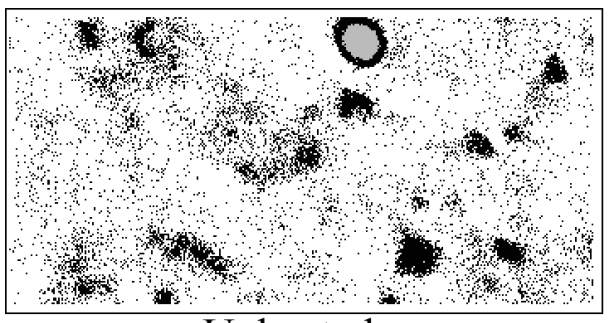

Unheated

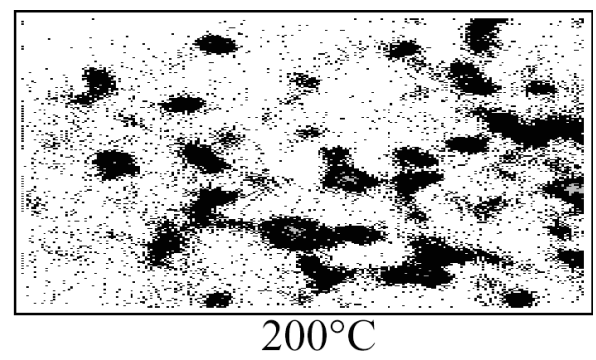

$200^{\circ} \mathrm{C}$

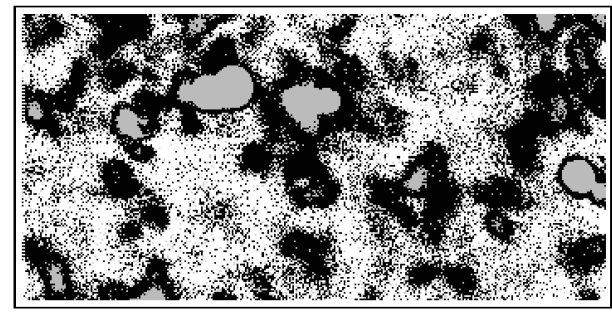

$400^{\circ} \mathrm{C}$

Table 4. Microcrack damage for thermally treated samples.

\begin{tabular}{ll}
\hline $\begin{array}{l}\text { Thermal treatment } \\
\text { temperature }\left({ }^{\circ} \mathrm{C}\right)\end{array}$ & $\begin{array}{l}\text { Microcrack } \\
\text { damage }(\%)\end{array}$ \\
\hline 28 & 14.24 \\
200 & 21.33 \\
400 & 34.77 \\
\hline
\end{tabular}

perspective of an optical image. In the case of an optical image, a crack will appear as a straight or bent line of finite length and width, which can be classified as intragranular or intergranular crack, cleavage crack, and grain-boundary crack. In the case of an ultrasonic image, microcracks appear in irregular shapes, and classification is not possible as in the case of an optical image. Thus it is preferable to use the word microcrack damage or damage for the defective regions displayed as images instead of microcrack. Considering the amplitude of the reflected ultrasonic waves, images have been classified into two groups as microcrack damage (amplitude <25\%) and macrocrack damage (amplitude $>25 \%$ ) (Nagaraja Rao 1996). In the images, microcrack damage is shown in black and macrocrack damage in gray. As the main objective of the investigation is to study microcrack development, no attempt is made here to analyse the various stages of macrocrack development. The areas of microcrack damage appear in two forms as random isolated points and as clusters. Cluster formation, growth, density, and coalescence control the overall mechanical behaviour of a rock material and are affected by stress and thermal treatment temperature.

In the images each pixel has an echo amplitude and gray level. There are 256 gray levels, where 0 represents total darkness (black) and 255 represents total brightness (white). The size of each pixel depends on the resolution of the stepper motor used for scanning the sample. In this particular study the resolution of each pixel is $114 \mu \mathrm{m}$. The number of pixels for each gray level was computed using image- processing software. Percent damage was calculated using the following formula:

$$
\text { damage }=\frac{(\text { number of pixels } \times \text { area of each pixel })}{\text { scanned area }} \times 100
$$

\section{Analysis of ultrasonic images of thermally treated granite}

Ultrasonic images for unheated and thermally treated granite samples are shown in Fig. 8. The computed microcrack damage for these three types of samples is given in Table 4. It is observed from Fig. 8 and Table 4 that the microcrack damage, cluster density, and coalescence increase with an increase in thermal treatment temperature.

Figure 9 shows the ultrasonic images taken at different stages for the unheated and thermally treated granite samples under uniaxial compression testing. The images show a distinct change in microcrack development at each stage. Microcrack damage, cluster density, and coalescence increase with an increase in stress and most of the clusters have coalesced as the failure stress is approached. From the images, microcrack damage was computed at different stages for the unheated and thermally treated samples and is given in Table 5, in which stresses are normalized with respect to the failure stress of the unheated granite sample. Figure 10 shows the variation of microcrack damage versus normalized stress for unheated and thermally treated granite samples. Considering Table 5 and Fig. 10, the following inferences are made:

(1) Thermal treatment increases microcrack damage, but when thermally treated samples are subjected to stress they show a lesser increase in damage compared to the unheated sample.

(2) In the case of unheated granite, cumulative damage increases with an increase in stress up to stage 5 .

(3) For the sample thermally treated to $200^{\circ} \mathrm{C}$, cumulative damage increases up to stage 4 , beyond which the damage remains almost constant. This implies that new cracks do not form beyond stage 4 and that the input energy is used for cluster growth and coalescence. 
Fig. 9. Ultrasonic images at different stages of deformation for unheated and thermally treated samples.

Unheated

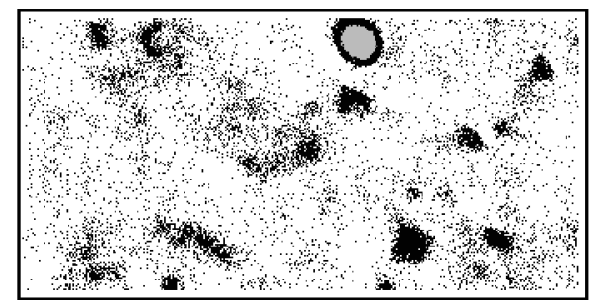

Stage 0

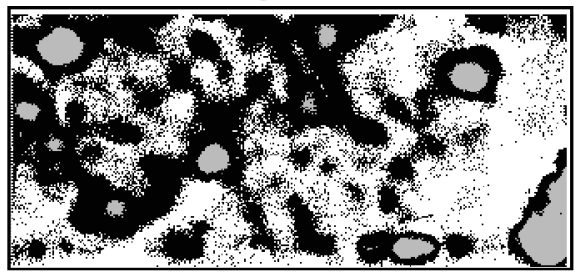

Stage 4

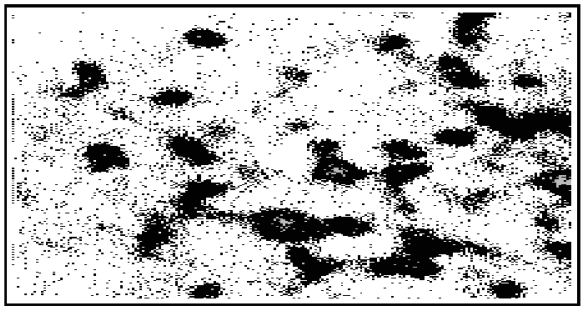

Stage 0

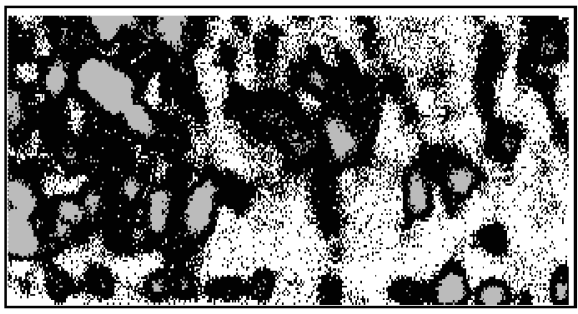

Stage 4

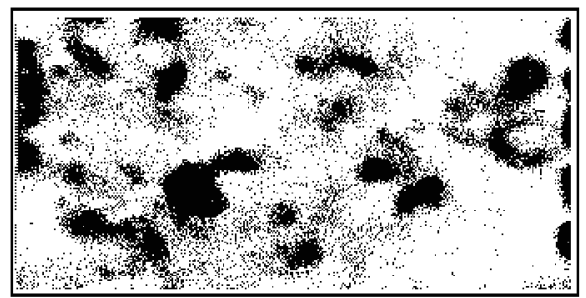

Stage 3

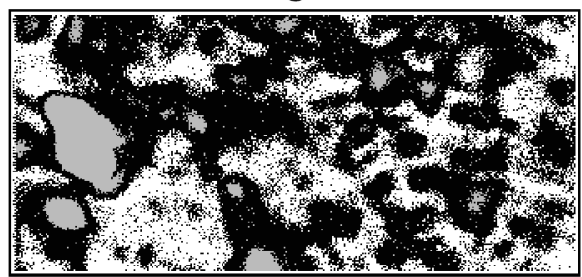

Stage 5

$200^{\circ} \mathrm{C}$ treated

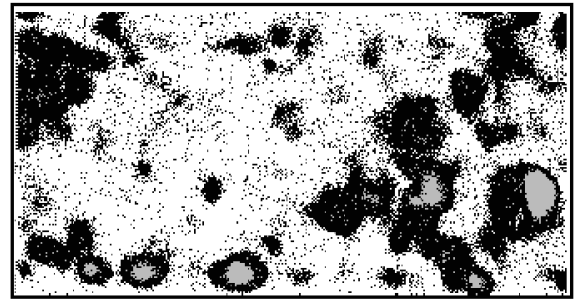

Stage 3

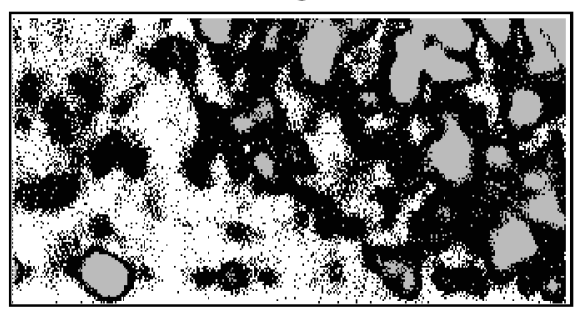

Stage 5

$400^{\circ} \mathrm{C}$ treated

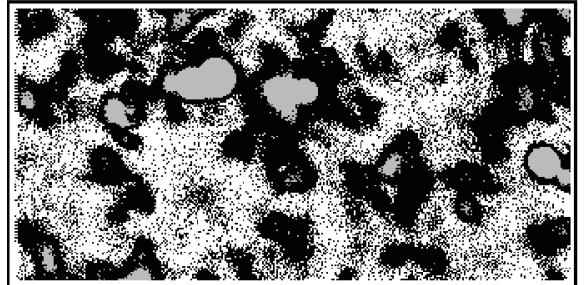

Stage 0

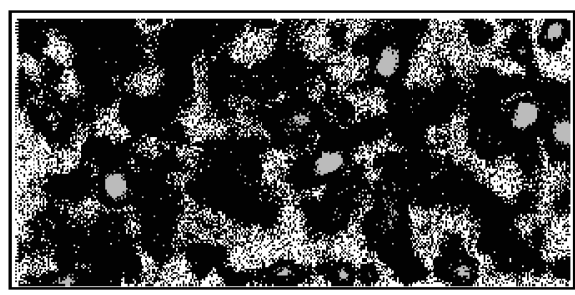

Stage 4

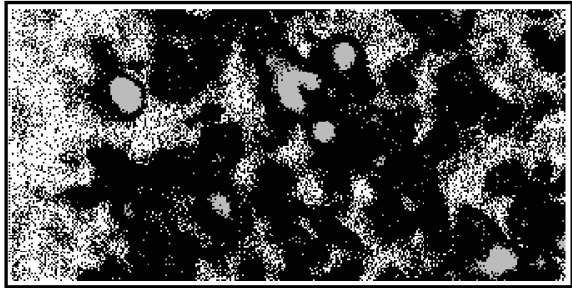

Stage 3

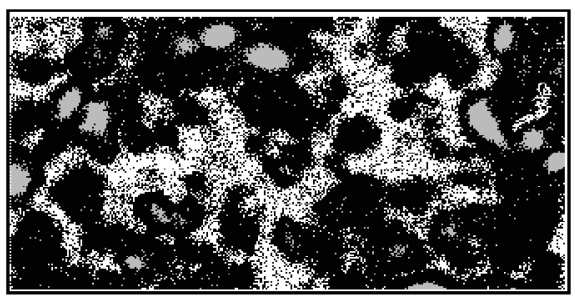

Stage 5 
Fig. 10. Variation of microcrack damage versus normalized stress for unheated and thermally treated samples.

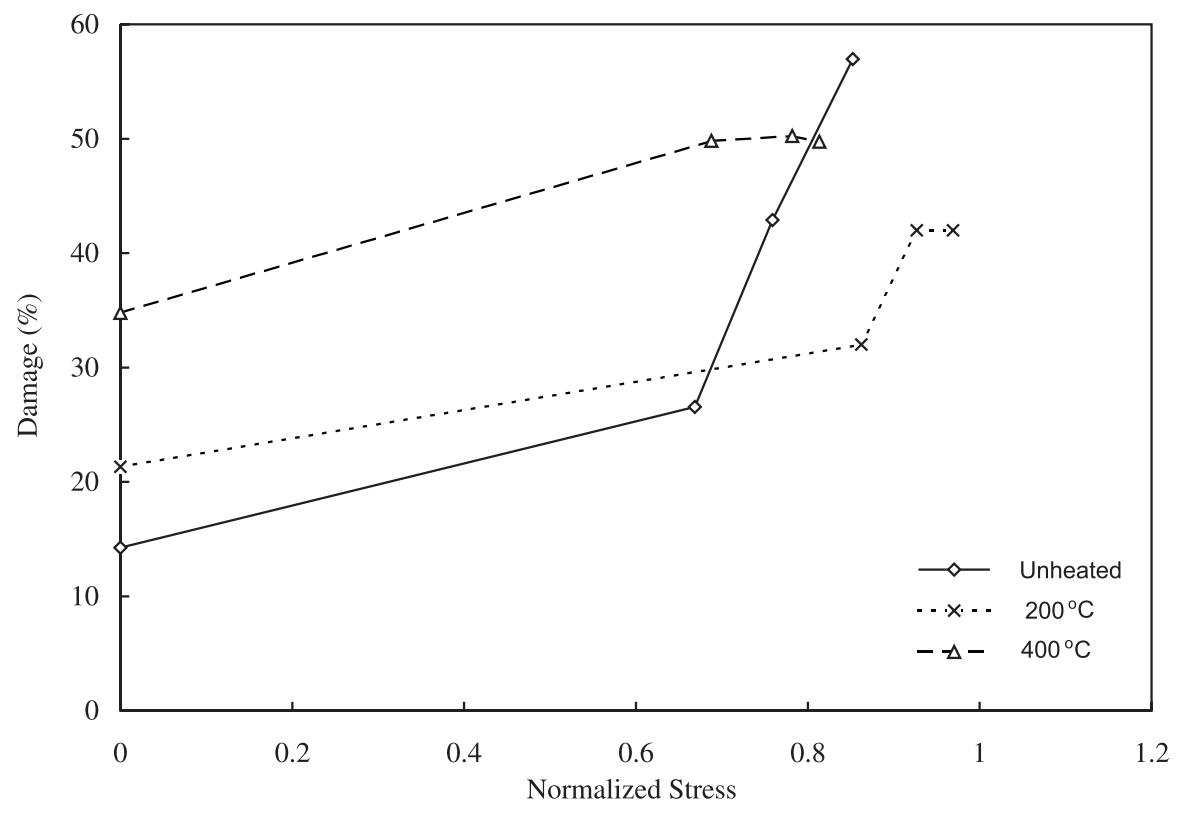

Table 5. Microcrack damage at different stages for unheated and thermally treated samples.

\begin{tabular}{llll}
\hline Stage & $\begin{array}{l}\text { Stress } \\
(\mathrm{MPa})\end{array}$ & $\begin{array}{l}\text { Normalized } \\
\text { stress }\end{array}$ & $\begin{array}{l}\text { Microcrack } \\
\text { damage }(\%)\end{array}$ \\
\hline Unheated $\left(\mathbf{2 8}^{\circ} \mathbf{C}\right)$ & & \\
S0 & 0 & 0 & 14.24 \\
S3 & 135.69 & 0.67 & 26.54 \\
S4 & 154.08 & 0.76 & 42.89 \\
S5 & 173.05 & 0.85 & 56.97 \\
Thermally treated to $200^{\circ} \mathbf{C}$ & & \\
S0 & 0 & 0 & 21.33 \\
S3 & 175.01 & 0.86 & 31.79 \\
S4 & 188.14 & 0.93 & 42.51 \\
S5 & 196.70 & 0.97 & 41.92 \\
Thermally treated to $400^{\circ} \mathbf{C}$ & & \\
S0 & 0 & 0 & 34.77 \\
S3 & 139.59 & 0.69 & 49.82 \\
S4 & 158.73 & 0.78 & 50.23 \\
S5 & 165.09 & 0.81 & 49.74 \\
\hline
\end{tabular}

Note: Stresses are normalized with respect to the mean failure stress of the unheated granite sample given in Table 3.

(4) In the case of the sample thermally treated to $400^{\circ} \mathrm{C}$, maximum damage of $50 \%$ occurs in stage 3 , beyond which it remains nearly constant.

Since the minerals present in granite do not have preferred orientations, it is assumed that microcracks produced during thermal treatment are distributed randomly throughout the cylindrical sample. When thermally treated samples are stressed, thermally induced microcracks that are favorably oriented are closed or propagate for a short distance, but some of the thermal cracks due to their unfavorable orientation are not affected by the applied stress. With the increase in stress, new microcracks originate in the presence of thermally induced cracks. These thermally induced cracks de- pending on their size, orientation, and density affect the initiation of stress-induced cracks. Therefore, the cumulative damage of thermally treated samples shows a different trend. In Fig. 10, experimental points are joined by lines and these lines may be approximated by suitable regression linescurves. For the unheated sample and the sample thermally treated to $200^{\circ} \mathrm{C}$, the trend may be approximated by exponential curves, whereas for the sample treated $400^{\circ} \mathrm{C}$ it is a linear fit. Keeping these approximations, it is possible to explain the observed variation in microcrack damage. One possible explanation for the observed result is to presume two different behaviours of the microcracks in samples treated to different temperatures. In the case of the granite sample thermally treated to $200^{\circ} \mathrm{C}$, the initial microcrack damage is greater than that for the unheated sample (Table 4), but the growth of damage with the increase in stress is less than that for the unheated sample. This indicates that there is a mechanism resisting the initiation of stress-induced cracks. In the case of the sample thermally treated to $400^{\circ} \mathrm{C}$, before the application of stress the damage was about $35 \%$. With the increase of stress the damage increases to about $50 \%$ at stage 3 , beyond which it remains nearly constant. Ultrasonic images of the sample thermally treated to $400^{\circ} \mathrm{C}$ are approximately the same at stages 3, 4, and 5 (Fig. 9). Here a large number of clusters are surrounded by microcracks. In general, it is expected that these microcracks and clusters would grow, coalesce, and form a macroscopic crack. Since the damage is approximately constant beyond stage 3 , it is infered that these microcracks are resisting the coalescence of clusters. In the case of the sample treated to $200^{\circ} \mathrm{C}$, thermal treatment retards the initiation of stress-induced microcracks. In the case of the sample treated to $400^{\circ} \mathrm{C}$, however, thermal treatment prevents an early coalescence of clusters. Thermal treatment increases microcrack damage, but when thermally treated granite samples are under stress they show less damage compared to unheated stressed samples. 
Fig. 11. Effect of thermal treatment temperature on cumulative events.

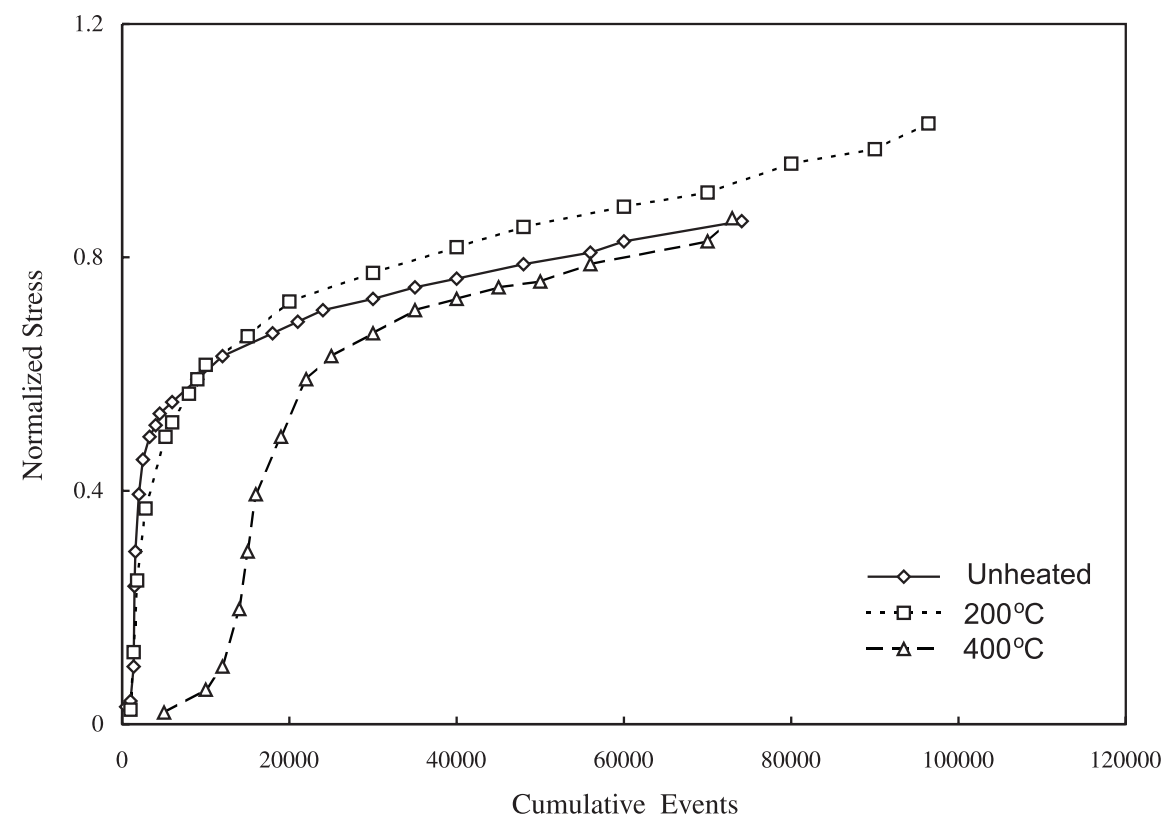

Table 6. Microcrack and macrocrack phases.

\begin{tabular}{lll}
\hline Phase & Event type & Peak amplitude $(\mathrm{dB})$ \\
\hline Microcrack initiation & $\alpha$ & $44-60$ \\
Microcrack extension & $\beta$ & $61-70$ \\
Macrocrack initiation & $\gamma$ & $71-80$ \\
Macrocrack extension & $\delta$ & $81-100$ \\
\hline
\end{tabular}

These observations suggest that the rock matrix becomes stronger in the presence of thermally induced microcracks.

\section{Acoustic-emission (AE) monitoring}

Ultrasonic images were taken at selected stress values where major changes in microcrack development are anticipated. To follow the microcrack development changes continuously, the AE monitoring technique was used. AEs were recorded using a $150 \mathrm{kHz}$ resonant sensor from unheated granite and granite thermally treated to $200^{\circ} \mathrm{C}$ and $400^{\circ} \mathrm{C}$ under uniaxial compression up to failure. Details of $\mathrm{AE}$ monitoring are given by Nagaraja Rao (1996). Ultrasonic images of unheated and thermally treated granite samples have shown that microcrack damage increases with an increase in temperature. It is expected that AE activity should also increase with an increase in stress for thermally treated samples, but the observed trend is different.

Figure 11 shows stress versus cumulative events for unheated and thermally treated granite samples. Stresses are normalized with respect to the failure stress of the unheated sample. It is interesting to note that higher stress is required for the generation of events in the case of granite thermally treated to $200^{\circ} \mathrm{C}$. For example, to produce 30000 cumulative events, the normalized stresses required are $0.73,0.77$, and 0.67 , respectively, for the unheated sample and the samples thermally treated to $200^{\circ} \mathrm{C}$ and $400^{\circ} \mathrm{C}$.

$\mathrm{AE}$ events are from both microcracks and macrocracks. Nagaraja Rao et al. (1999), based on parametric analysis,
Fig. 12. Characteristic feature of $\alpha, \beta, \gamma$, and $\delta$ events.

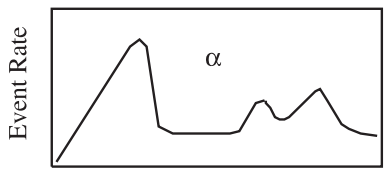

Stress

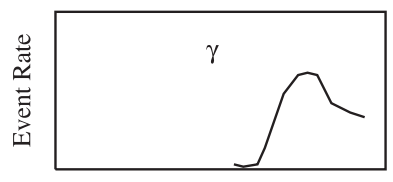

Stress

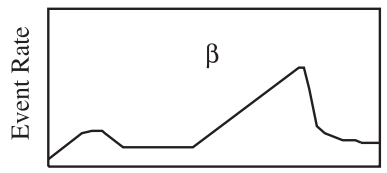

Stress

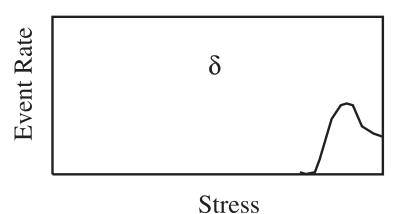

classified the $\mathrm{AE}$ events into microcrack and macrocrack phases, and their classification is given in Table 6.

The four types of events listed in Table 6, i.e., $\alpha, \beta, \gamma$, and $\delta$, initiate at a particular stress level. Their growth rate increases slowly with an increase in stress; beyond a certain stress level their event rate increases rapidly and their characteristic growth rate is shown in Fig. 12. Since these four types of events appear at different stress levels, it is possible to define crack-initiation stress separately for $\alpha, \beta, \gamma$, and $\delta$ events. Crack-initiation stress is the stress level at which a particular type of event initiates. This stress was determined for unheated and thermally treated samples and is plotted in Fig. 13 (Nagaraja Rao 1996), which shows that both microcrack and macrocrack phases initiate at different stress levels. The following observations are made about the development of the different phases:

(1) Microcrack phase: For thermally treated samples $\alpha$ type events initiate at a lower stress level, but $\beta$-type events initiate at a higher stress level compared with that for an unheated sample.

(2) Macrocrack phase: For the unheated sample and the sample thermally treated to $400^{\circ} \mathrm{C}$, both $\gamma$ - and $\delta$-type events 
Fig. 13. Crack-initiation stress for $\alpha, \beta, \gamma$, and $\delta$ events.

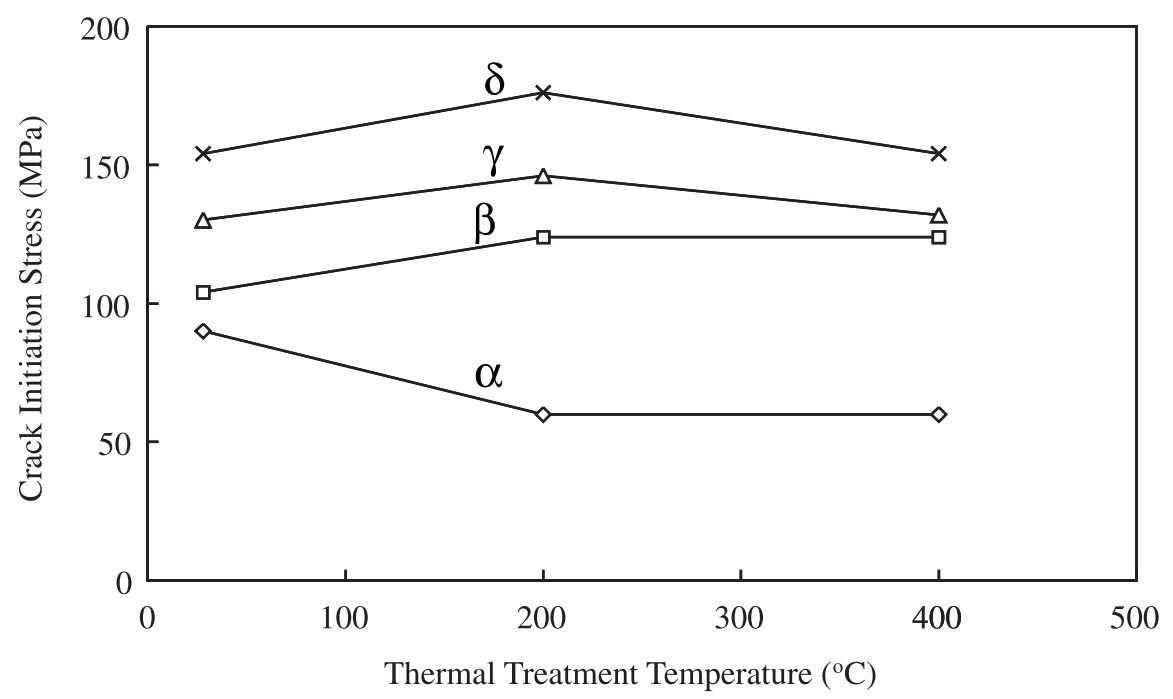

are initiated at the same stress level; however, for the sample thermally treated to $200^{\circ} \mathrm{C}$ the initiation stress occurs at a higher stress.

(3) In the case of the sample thermally treated to $200^{\circ} \mathrm{C}$, microcrack ( $\beta$-type) and macrocrack $(\gamma$ and $\delta$ ) events are initiated at a higher stress level than that for the unheated sample and the sample thermally treated to $400^{\circ} \mathrm{C}$.

Analysis of AE results clearly showed that the development of microcracks and macrocracks is affected by thermal treatment.

From the results of uniaxial compression tests, ultrasonic $\mathrm{C}$-scan imaging, and AE monitoring it is evident that thermal treatment affects the strength of the granite and the development of microcracks and macrocracks. Granite samples were prepared from a single block and every care was taken in the selection, preparation, and testing of the samples. The observed experimental results cannot be attributed totally to the heterogeneity of the samples.

Ultrasonic velocity, axial strain, and ultrasonic images clearly show that thermal treatment introduces microcracks. Microcracks are the defects in a rock material. It was expected that the introduction of microcracks in a granite sample would reduce the uniaxial compressive strength and accelerate the development of microcracks and macrocracks. However, the observed trend is different. Uniaxial compressive strength showed that the sample thermally treated to $200^{\circ} \mathrm{C}$ has the highest strength and the strength of the sample thermally treated to $400^{\circ} \mathrm{C}$ is similar to that of the unheated sample.

Fracturing in rocks under compressive stress is a result of nucleation, growth, interaction, and coalescence of numerous microcracks. To understand the affect of thermally induced microcracks on the growth of stress-induced microcracks, three techniques were adopted, namely measurement of deformation, ultrasonic C-scan imaging, and $\mathrm{AE}$ monitoring. Results available from these techniques vary, but the observations supplement one another. Information obtained from the deformation measurement is more macroscopic in nature, whereas ultrasonic C-scan imaging and $\mathrm{AE}$ monitoring give details of microscopic changes. Inelastic strain is a measure of microcrack development and was estimated from the volumetric strain. In the case of the sample thermally treated to $200^{\circ} \mathrm{C}$, inelastic strain is less than those of the unheated sample and the sample thermally treated to $400^{\circ} \mathrm{C}$.

Microcrack damage was estimated quantitatively from the ultrasonic images. Before the application of stress the microcrack damage for the unheated sample and the samples thermally treated to $200^{\circ} \mathrm{C}$ and $400^{\circ} \mathrm{C}$ is in the ratio of $1: 1.50: 2.44$, respectively. When these samples are stressed the increase in damage does not follow the initial trend and there is a lower increase in damage with the increase of stress for thermally treated samples. For the sample thermally treated to $200^{\circ} \mathrm{C}$ the damage does not increase beyond stage 4 . The initial damage of the sample thermally treated to $400^{\circ} \mathrm{C}$ was more than twice that of the unheated, unstressed granite sample. When the sample is stressed the damage does not increase in the same proportion as that for an unheated sample. In fact, for the sample thermally treated to $400^{\circ} \mathrm{C}$ there is hardly any increase in damage beyond stage 3. Despite the initial high microcrack damage, the uniaxial compressive strength of the sample thermally treated to $400^{\circ} \mathrm{C}$ is comparable to that of an unheated sample.

$\mathrm{AE}$ monitoring has shown that higher stress is required for the generation of events for the sample thermally treated to $200^{\circ} \mathrm{C}$. Microcracks and macrocracks are initiated at different stress levels depending on thermal treatment temperature. For the sample thermally treated to $200^{\circ} \mathrm{C}$, microcracks and macrocracks are initiated at higher stress levels than that for the unheated sample. Although the initial microcrack damage for the sample thermally treated to $400^{\circ} \mathrm{C}$ is higher than that for the unheated sample, microcracks and macrocracks initiate at the same stress level.

Considering ultrasonic imaging and the AE results, it is evident that the thermal treatment resists crack initiation and growth, which implies that the material becomes stronger, as is evident from the results of uniaxial compression tests. Microcrack development occurs in both the unheated and thermally treated granites, but there is a basic difference: for the unheated sample, stress-induced cracks develop in the 
absence of thermally induced cracks, whereas in the case of thermally treated samples stress-induced cracks initiate and grow in the presence of thermally induced cracks. From the results it is apparent that thermally induced microcracks resist the initiation and growth of stress-induced microcracks and this is a major contributing factor to the variation in strength values under uniaxial compression.

\section{Discussion}

As indicated in the introduction, the mechanical properties of ceramics can be improved by introducing a defective structure. Similar behaviour was observed in rock materials as shown by the experimental results. The mechanism responsible for the improvement in the mechanical properties of rock materials can be linked to the behaviour of ceramics. The improvement in mechanical properties of ceramics is as a result of the concept of toughening, which is the resistance to crack initiation and propagation. The experimental evidence discussed in the paper does not directly explain the possible toughening mechanism operating in thermally treated samples of granite. Also, there is very little information available on the toughening mechanism of rock materials. Rocks are natural brittle materials that contain complex silicates bonded by ionic and covalent bonds. Ceramics are synthetic materials containing silicates, carbides, nitrides, etc. bonded by ionic and covalent bonds, and they are also brittle materials. The mechanical behaviour of rock is almost identical to that of ceramics, and extensive literature is available on the toughening of ceramics (Clarke and Faber 1987; Evans and Faber 1984; Lawn 1983, 1993; McMeeking and Evans 1981). Since there is a similarity between rock and ceramic materials, the information available on the toughening mechanisms of ceramic materials should also be applicable to rock materials. Some of the possible toughening mechanisms for rock materials are discussed in the following section.

\section{Toughening mechanisms}

One of the objectives of a materials scientist working with ceramics is to improve the properties of brittle polycrystalline ceramics. By tailoring the microstructure, it is possible to introduce an interactive defect structure that acts as an effective restraint on crack propagation and thus enhances the material toughness (Lawn 1993). Various toughening mechanisms have been proposed, and the essence of all the mechanisms is to resist the propagation of cracks, a brief discussion of which is given here.

Crack deflection - Fracture toughness can be increased by causing a propagating crack to deviate out of the crack plane. Deflection may arise due to interaction with residual stresses, grain boundaries, and secondary phases. The more tortuous the paths of the crack, the higher the toughening will be. Thermal treatment introduces residual stresses that behave as obstacles to the propagation of cracks.

Crack interface bridging - One general approach to increasing the fracture resistance of a brittle solid is to retard or prevent the crack opening by bridging the crack walls as the crack is driven through the material. As the bridges are loaded they provide a restraining force against further open- ing of the crack and thereby act as a crack closure force. Such crack bridging is some times referred to as ligament or fiber toughening. It is a widely occurring phenomenon that can act over a wide range of scales.

Process-zone toughening — The propagation of a crack arises due to the separation of surfaces near the crack tip. If the energy-dissipative processes occur near the crack tip rather than at the surface separation, then toughness of the material can be increased. Thus arises the idea of a "process zone" at the crack tip within which discrete "energy sinks" are activated. The role of the process zone simply becomes one of "shielding" the crack tip from the remotely applied stress, thereby necessitating a higher applied stress to further propagate the crack. Two examples of process-zone toughening in ceramics are (i) transformation toughening, and (ii) stress-induced microcracking. Phase transformation of Martensite from tetragonal to monoclinic zircona is triggered by the stress field of the propagating crack and the unit cell volume increases by about $4-5 \%$. Residual strain developed during phase transformation tends to limit the crack opening, with the result that toughness increases. This mechanism is not possible for rock materials, as the phase transformation cannot occur by the residual stress field. For stress-induced microcracking, when the crack is loaded, microcracks form near the crack tip because of the stress field of the crack tip and residual tensile stresses present due to elastic mismatch between the phases. The microcrack zone formed around the crack tip is called a process zone or frontal process zone (Atkinson 1987; Barber and Meredith 1990; Evans and Faber 1984). As the crack advances, microcracks originally in front of the crack are now left behind, thereby building up a wake region of microcracks behind the crack tip (Fig. 14). Toughening is due to both the frontal process zone and the wake region. The sources of toughening are as follows: $(i)$ part of the input energy is used for generating the process zone and, as a result, less energy is available for the propagation of cracks; (ii) formation of microcracks results in dilatational strain, and opening of microcracks introduces compressive stresses on the crack faces; and (iii) both the frontal process zone and the wake region contribute to toughening.

Evans and Faber (1984) and McMeeking and Evans (1981) have shown that the presence of the wake region results in a toughness that exceeds the toughness achieved with the frontal process zone. Labuz et al. (1991), after applying suitable corrections for the nonlinear zone, have reported that in the case of limestone, plane strain fracture toughness $\left(K_{\mathrm{IC}}\right)$ increases with an increase in thermally induced damage. They are of the opinion that the extra energy dissipated in fracturing the microcracked rock may be due to a toughening mechanism. From our work we have observed that after applying a correction for nonlinearity, $K_{\mathrm{IC}}$ increases with an increase in the temperature of the thermal treatment; the fracture toughness values are given in Table 7.

As in the case of ceramics, crack deflection and stressinduced microcracking are also likely toughening mechanisms in rock materials. In addition to these mechanisms, the opening of microcracks can also provide toughening and the two possible cases are discussed as follows.

Let us consider a case where only thermally induced cracks are present in a rock material. Figure 15 shows a 
Fig. 14. Formation of the process zone and wake region.

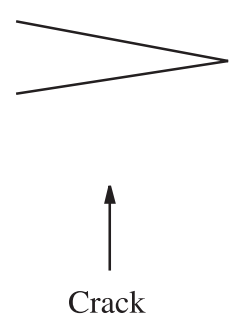

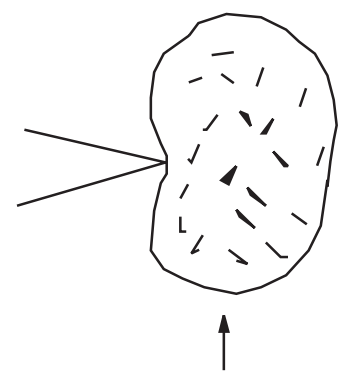

Process zone

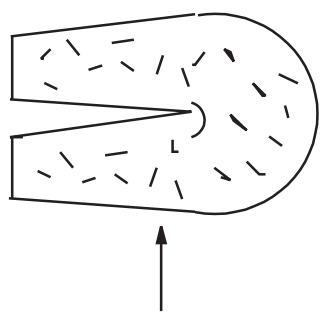

Wake

Fig. 15. Opening of microcracks in a constrained volume.

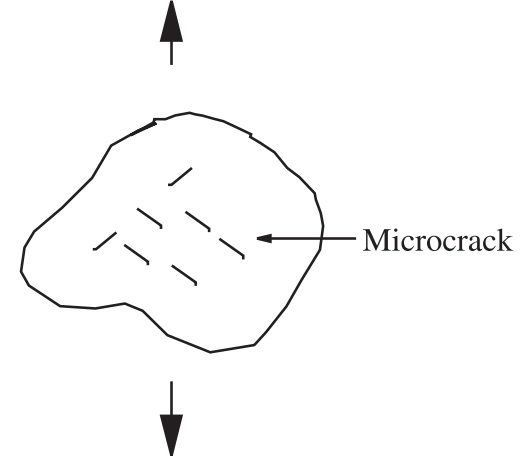

Table 7. Fracture toughness of unheated and thermally treated granite.

\begin{tabular}{ll}
\hline $\begin{array}{l}\text { Thermal treatment } \\
\text { temperature }\left({ }^{\circ} \mathrm{C}\right)\end{array}$ & $\begin{array}{l}\text { Plane strain fracture } \\
\text { toughness }\left(\mathrm{MPa} \mathrm{m}{ }^{1 / 2}\right)\end{array}$ \\
\hline Unheated & 2.73 \\
200 & 2.83 \\
400 & 1.22 \\
\hline
\end{tabular}

grain containing thermally induced microcracks. Under the influence of tensile stress, opening of these cracks in a constrained volume induces compressive stress on the neighboring areas, which in turn resist the initiation of stress-induced microcracks. Here toughening arises due to the opening of microcracks.

Consider another possibility where a macrocrack is surrounded by a large number of microcracks (Fig. 16). Here the crack moves in an environment containing microcracks. The input mechanical energy is used for $(i)$ propagation of the crack, and (ii) irreversible openings of the microcracks. Opening of the microcracks induces compressive stresses on the crack faces, which increases the resistance for crack propagation.

Microcracks play a dual role (Labuz et al. 1991). They can stabilize a macrocrack by softening the material around the tip, thereby reducing the effect of the applied load and producing a shielding mechanism. Microcracks can also reduce the resistance of the material to fracture, causing the crack to initiate at a lower load and producing a degradation mechanism. The stress intensity at the crack tip can decrease producing the shielding effect or increase simulating an antishielding (degradation) effect depending on the position of the microcracks. Considering these concepts, the variation in uniaxial compressive strength of thermally treated granite samples can be explained. Thermally induced microcracks depending on the orientation, density, and spacing of microcracks show a dual role, i.e., toughening and degradation. Degradation corresponds to the coalescence of microcracks forming a macroscopic crack. With the increase of damage initially microcracks provide toughening. Later when the cracks are close to each other, both crack coalescence and toughening occur. Lastly, when the cracks are very close to each other, only crack coalescence takes place, resulting in degradation. With an increase in the temperature of thermal treatment there is a transformation from toughening to degradation which can be represented as

$$
\begin{aligned}
& \text { toughening } \rightarrow \text { toughening and degradation } \rightarrow \\
& \text { degradation }
\end{aligned}
$$

Figure 17 shows uniaxial compressive strength and microcrack damage versus thermal treatment temperature. The microcrack damage was determined for an unheated sample and samples thermally treated to $200^{\circ} \mathrm{C}$ and $400^{\circ} \mathrm{C}$ from ultrasonic images and the results were extrapolated to $600^{\circ} \mathrm{C}$ by a linear fit. Microcrack damage increases with an increase in the thermal treatment temperature. The uniaxial compressive strength curve is divided into two zones. Zone $\mathrm{A}$ is a toughening zone in which thermally induced microcracks produce a toughening effect that reaches a maximum for the granite sample thermally treated to $200^{\circ} \mathrm{C}$. In zone $\mathrm{B}$ toughening decreases with an increase in the amount of damage. For the sample thermally treated to $400^{\circ} \mathrm{C}$, due to high crack density both toughening and degradation mechanisms seem to operate equally. Reduced toughening 
Fig. 16. Toughening by microcrack opening.

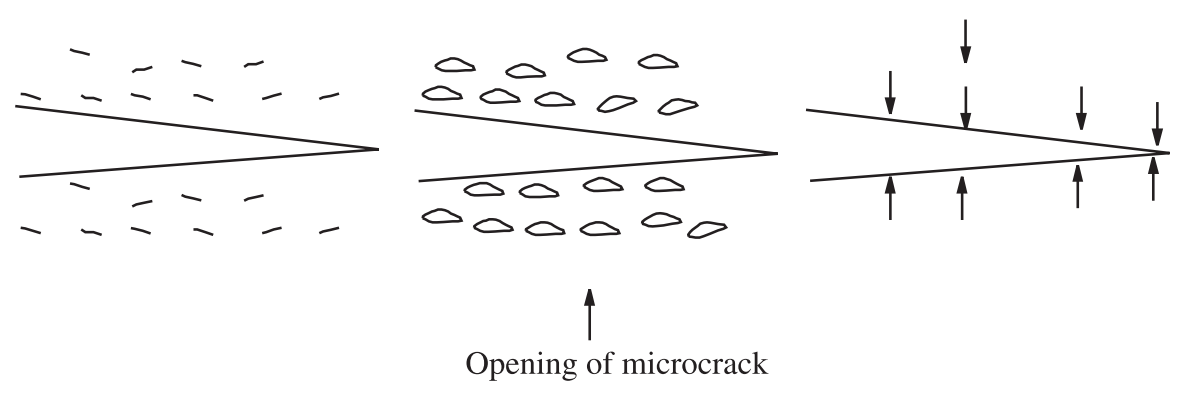

Fig. 17. Toughening and degradation zones under uniaxial compression.

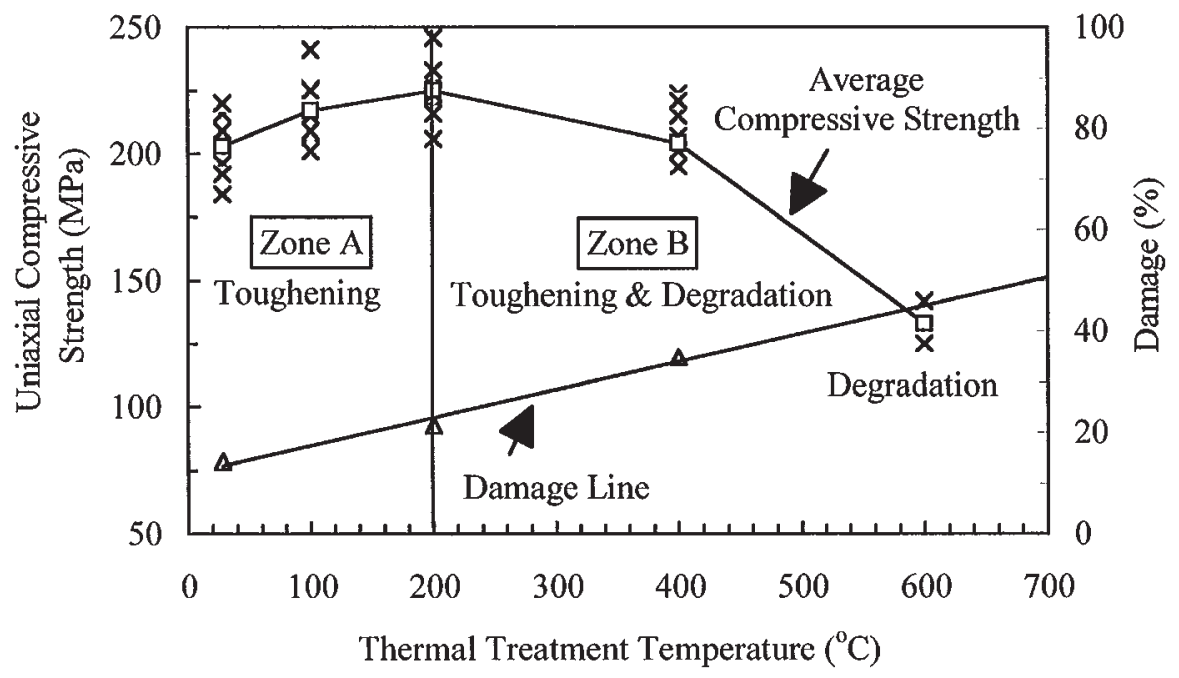

may be due to less constraint. Around $400^{\circ} \mathrm{C}$ most of the grains are microcracked. Cracked grains may act as boundaries. Toughening due to the crack wake region is reduced due to the frequent occurrence of boundaries (Evans and Faber 1984). The strength of the sample thermally treated to $400^{\circ} \mathrm{C}$ is comparable to that of the unheated sample. For the sample thermally treated to $600^{\circ} \mathrm{C}$, only the degradation mechanism operates, which reduces the strength.

Uniaxial compression tests on thermally treated granite samples have clearly indicated the dual role of microcracks, i.e., toughening and degradation. The mechanisms of toughening and degradation are summarized in Table 8.

As already mentioned, it is easy to explain the deterioration of mechanical properties of rock materials, but not the improvement in mechanical properties. We have attempted to explain the observed experimental observations based on the toughening mechanisms of ceramics. It has been assumed that one or a combination of toughening mechanisms may be operating.

\section{Conclusions}

The effect of thermally induced microcracks on the strength and growth of stress-induced microcracks and macrocracks under uniaxial compressive stress conditions was studied for granite samples. Important conclusions of the experimental studies are as follows:

(1) Thermal treatment of granite affects the deformation and strength under uniaxial compressive stress conditions.
Table 8. Toughening and degradation mechanisms of thermally treated granite.

\begin{tabular}{ll}
\hline $\begin{array}{l}\text { Thermal treatment } \\
\text { temperature }\left({ }^{\circ} \mathrm{C}\right)\end{array}$ & Mechanism \\
\hline Unheated & No toughening \\
100 & Toughening \\
200 & Toughening maximum \\
400 & Toughening + degradation \\
600 & Degradation \\
\hline
\end{tabular}

The granite sample thermally treated to $200^{\circ} \mathrm{C}$ showed the highest strength. The strength of granite thermally treated to $400^{\circ} \mathrm{C}$ is comparable to that of unheated granite, although it contains microcracks due to thermal treatment.

(2) Ultrasonic images for unheated and thermally treated samples showed that microcrack damage increases with an increase in thermal treatment temperature, but when thermally treated samples are subjected to stress they show less damage than unheated samples. Analysis of ultrasonic images showed that in the case of the sample thermally treated to $200^{\circ} \mathrm{C}$, thermal treatment retards the initiation of stressinduced microcracks, whereas in the case of the sample thermally treated to $400^{\circ} \mathrm{C}$ it prevents the early coalescence of clusters of microcracks.

(3) Acoustic emission monitoring indicates that in the case of the sample thermally treated to $200^{\circ} \mathrm{C}$, microcrack and macrocrack events are initiated at a stress level higher 
than that for the unheated sample and the sample thermally treated to $400^{\circ} \mathrm{C}$. In the case of the sample thermally treated to $400^{\circ} \mathrm{C}$, although the microcrack damage is high due to thermal treatment, the nucleation of both microcracks and macrocracks occurs at a stress level similar to that of the unheated sample.

(4) It is suggested that resistance to crack growth can be explained by toughening mechanisms. Toughening arises due the generation and opening of microcracks. Opening of cracks induces compressive stresses, thereby increasing the resistance for crack initiation and propagation. Toughening and degradation mechanisms operate depending on the orientation, density, and spacing of microcracks, and degradation corresponds to the coalescence of microcracks leading to the formation of a macroscopic crack. With the increase of damage, microcracks initially provide toughening and when the crack density increases both crack coalescence and toughening occur. Lastly, when microcracks are very close to each other, only then does crack coalescence occur and the degradation mechanism predominates.

(5) Uniaxial compression tests on unheated and thermally treated granite samples have clearly established the dual role of microcracks, which operate in the toughening and degradation mechanisms. Toughening is responsible for the increase in strength of the granite sample thermally treated to $200^{\circ} \mathrm{C}$. For the granite sample thermally treated to $400^{\circ} \mathrm{C}$, both toughening and degradation occur together, resulting in strength comparable to that of the unheated sample.

\section{Acknowledgements}

The first author is extremely thankful to Dr. N.M. Raju, former director of the National Institute of Rock Mechanics (NIRM), for keen interest and constant encouragement in the investigation. He is also thankful to Prof. R.N. Gupta, director of NIRM, for permission to publish this paper. Thanks to Mr.Udayakumar and Mr. Abdul Majid for their help in conducting the experiments.

\section{References}

Alm, O., Jaktlund, L.-L., and Kou, S.-q. 1985. The influence of microcrack density on the elastic and fracture mechanical properties of stipa granite. Physics of the Earth and Planetary Interiors, 40: 161-171.

Atkinson, B.K. 1987. Fracture mechanics of rock. Academic Press, London.

Barber, D.J., and Meredith, P.G. 1990. Deformation processes in minerals, ceramics and rocks. Unwin Hyman, London.

Bauer, S.J., and Johnson, B. 1979. Effects of slow uniform heating on the physical properties of Westerly and charcoal granite. In Proceedings of the 20th U.S. Symposium on Rock Mechanics, 4-6 June, Austin, Texas, pp. 7-18.

Clarke, D.R., and Faber, K.T. 1987. Fracture of ceramics and glasses. Journal of Physics and Chemistry of Solids, 48(11): 1115-1157.

Duclos, R., and Paquet, J. 1991. High temperature behaviour and strain rate on compressive strength and $K_{\text {IC }}$ toughness of partially glassy basalts at atmospheric pressure. International Journal of Rock Mechanics and Mining Sciences and Geomechanics Abstracts, 28(1): 71-76.
Etienne, F.H., and Poupert, R. 1989. Thermally induced microcracking in granites, characterisation and analysis. International Journal of Rock Mechanics and Mining Sciences and Geomechanics Abstracts, 26(2): 125-134.

Evans, A.G., and Faber, K.T. 1984. Crack-growth resistance of microcracking brittle materials. Journal of the American Ceramic Society, 67(4): 256-260.

Falls, S.D., Young, R.P., Carlson, S.R., and Chow, T. 1992. Ultrasonic tomography and acoustic emission in hydraulically fractured Lac due Bonnet granite. Journal of Geophysical Research, 97(B5): 6867-6889.

Janson, D.P., Chow, T., Hutchins, D.A., and Young, R.P. 1992. Ultrasonic tomographic imaging of anisotropic solids. Acoustical Imaging, 19: 59-63.

Janson, D.P., Carlson, S.R., Young, R.P., and Hutchins, D.A. 1993. Ultrasonic imaging and acoustic emission monitoring of thermally induced microcracks in Lac du Bonnet granite. Journal of Geophysical Research, 98(B12): 22231 - 22243.

Knollman, G.C., and Hartog, J.J. 1983. Acoustic imaging of 3D carbon/carbon billets. Materials Evaluation, 41: 1186-1193.

Knollman, G.C., and Yee, R.C. 1988. Ultrasonic image evaluation of microstructural damage accumulation in materials. Experimental Mechanics, 32(6): 110-116.

Knollman, G.C.,Weaver, J.L., Hartog, J.J., and Bellin, J.L. 1975. Real time ultrasonic imaging methodology in non-destructive testing. Journal of the Acoustical Society of America, 58(2): 455-470.

Knollman, G.C., Carver, D., and Hartog, J.J. 1978. Acoustic imaging of composites - the ultrasonic test that requires no interpretation. Materials Evaluation, 36: 41-47.

Kranz, R.L., and Scholz, C.H. 1977. Critical dilatant volume of rocks at the onset of tertiary creep. Journal of Geophysical Research, 82(30): 4893-4898.

Labuz, J.F., Chen, C.N., and Berger, D.J. 1991. Microcrackdependent fracture of damaged rock. International Journal of Fracture, 51: 231-240.

Lawn, B. 1983. Physics of fracture. Journal of the American Ceramic Society, 66(2): 83-91.

Lawn, B. 1993. Fracture of brittle solids. Cambridge University Press, New York.

McMeeking, R.M., and Evans, A.G. 1981. Mechanics of transformation-toughening in brittle materials. Journal of the American Ceramic Society, 65(5): 242-274.

Nagaraja Rao, G.M. 1996. Studies on strain rate and thermal exposure effects on initiation and growth of cracks in granite by ultrasonic and acoustic emission techniques. Ph.D. thesis, Indian Institute of Science, Bangalore, India.

Nagaraja Rao, G.M., Raju, N.M., and Murthy, C.R.L. 1995. Ultrasonic imaging of microcrack damage in rocks. In Proceedings of the 8th Asia-Pacific Conference on Nondestructive Testing (8th APCNDT), 11-14 Dec. 1995, Taipei, Taiwan, pp. 281-286.

Nagaraja Rao, G.M., Murthy, C.R.L., and Raju, N.M. 1999. Characterization of micro and macro cracks in rocks by acoustic emission. In Acoustic emission: standards and technology update. Edited by S.J. Vahaviolos. American Society for Testing and Materials, Special Technical Publication STP 1353, pp. 141-155.

TomxGrubber, J.J., Smith, J.M., and Brockelman, R.H. 1982. U1trasonic velocity $\mathrm{C}$-scan for ceramic and composite materials characterisation. Materials Evaluation, 40(1): 90-96.

Young, R.P. 1993. Seismic method applied to rock mechanics. ISRM News Journal, 1(3): 4-18. 
Copyright $\odot 2003$ EBSCO Publishing 